\title{
Insulin can block apoptosis by decreasing oxidative stress via phosphatidylinositol 3-kinase- and extracellular signal-regulated protein kinase-dependent signaling pathways in HepG2 cells
}

\author{
Shinhae Kang ${ }^{1}$, Jihoon Song ${ }^{1}$, Heekyoung Kang, Sejae Kim ${ }^{1}$, Youngki Lee and Deokbae Park
}

Department of Medicine, College of Medicine, Institute of Basic Science and ${ }^{1}$ Department of Biology, College of Natural Science, Cheju National University, Ara-1, Cheju, 690-756, South Korea

(Correspondence should be addressed to D Park, Department of Medicine, College of Medicine, Cheju National University, Ara-1, Cheju, 690-756, South Korea; Email: parkdb@cheju.ac.kr)

\begin{abstract}
Objective: Insulin has well-known activities in controlling energy metabolism, cellular proliferation and biosynthesis of functional molecules to maintain a biological homeostasis. Recently, several studies have suggested that insulin may protect cells from apoptosis in different cell lines; however, little is known about the nature of its anti-apoptotic activity. In many clinical disorders, including type 2 diabetes mellitus, oxidative stress and the production of reactive oxygen species (ROS) is increased. With these facts as a background, we examined here whether insulin protects HepG2 cells from apoptosis by decreasing oxidative stress and, if so, which signaling steps are involved in this process.

Methods: Intracellular DNA content, the degree of nuclear condensation or poly(ADP-ribose) polymerase hydrolysis was measured to verify the occurrence of apoptotic events. Caspase- 3 activity and ROS accumulation within cells were also measured. Western blot analysis was performed to identify signaling molecules activated in response to insulin.

Results: Serum starvation resulted in a marked accumulation of ROS, activation of caspase-3, and subsequent apoptotic cell death which were, in turn, markedly blocked by the addition of insulin. The anti-apoptotic activity of insulin was sensitive to blockade of two different signaling steps, activations of phosphatidylinositol 3-kinase (PI3 kinase) and extracellular signal-regulated protein kinase (ERK).

Conclusion: Insulin exerts an anti-apoptotic activity by suppressing the excessive accumulation of ROS within cells through signaling pathways including stimulation of PI3 kinase and ERK in HepG2 cells.
\end{abstract}

European Journal of Endocrinology 148 147-155

\section{Introduction}

Insulin has a variety of functions such as glucose uptake, glycogen biosynthesis, inhibition of lipolysis and stimulation of cellular proliferation. It can also protect cells from apoptosis mediated by growth factor removal in different cell lines $(1-3)$. We have recently investigated the anti-apoptotic function of insulin and its related signaling pathways in Chinese hamster ovary cells expressing wild-type human insulin receptors (CHO-IR) $(4,5)$. Although a number of molecules involved in the prevention or induction of apoptosis have been identified, the mechanisms by which insulin participates in this process remain largely unknown.

Reactive oxygen species (ROS) have been implicated as important pathologic mediators in many clinical disorders (6), including type 2 diabetes mellitus $(7,8)$. In addition, oxidative stress disrupts insulin-induced signaling events such as insulin receptor tyrosine phosphorylation, insulin receptor substrate-1 (IRS-1) phosphorylation and activation of phosphatidylinositol 3-kinase (PI3 kinase) (9) as well as redistribution of IRS-1 and PI3 kinase in adipocytes (10). However, conflicting results on the effect of $\mathrm{H}_{2} \mathrm{O}_{2}$ on insulin signaling are also available. $\mathrm{H}_{2} \mathrm{O}_{2}$ mimics the stimulatory effects of insulin on glucose transport and lipid synthesis in adipocytes $(11,12)$ and insulin transiently generates $\mathrm{H}_{2} \mathrm{O}_{2}$ via NADPH oxidase, which is integral to activation of the insulin signaling cascades in adipocytes (13). Insulin-induced generation of $\mathrm{H}_{2} \mathrm{O}_{2}$ reversibly inhibits protein-tyrosine phosphatase 1B, thereby enhancing the early insulin action cascades (14). So 
far there has been no general agreement on which oxidative stress affects insulin signaling and its physiological functions, or on which insulin modulates ROS generation.

Following insulin binding, the insulin receptors undergo activation of their intrinsic tyrosine kinase function and subsequent stimulation of signaling molecules (15). We have reported that insulin delayed apoptosis induced by serum starvation (4), by a mechanism that is dependent on short-lived farnesylated proteins in CHO-IR cells (5). However, there is little evidence as to whether insulin really acts as a survival factor in physiological cell systems expressing intrinsic insulin receptors. With these facts as a background, we examined whether insulin exerts an anti-apoptotic activity and, if so, which signaling steps are important for completing this process in HepG2 cells expressing intrinsic insulin receptor molecules.

\section{Materials and methods}

\section{Materials}

Human recombinant insulin, PD98059, SB202190, the fluorogenic caspase-3 substrate, Ac-DEVD-AMC, the caspase inhibitor, z-DEVD-fmk and propidium iodide, 2',7'-dichlorofluorescin diacetate (H H $_{2}$ DCFDA) were obtained from Calbiochem (La Jolla, CA, USA). Wortmannin, Dulbecco's modified Eagle's medium (DMEM), Dulbecco's-phosphate-buffered saline (DPBS) and trypsin-EDTA solution were obtained from Sigma Chemical Corp. (St Louis, MO, USA), and fetal bovine serum (FBS) from Life Technologies Inc. (Rockville, MD, USA). Monoclonal antibodies against phospho-ERK1/2 (E-4), phospho-C-Jun $\mathrm{NH}_{2}$ terminal kinase (phospho-JNK) (G-7), phospho-p38Map kinase (D-8), ERK2 (D-2) and polyclonal antibodies against phospho-Akt1 (ser473) and poly(ADP-ribose) polymerase (PARP) (H-250) were from Santa Cruz Biotechnology (Santa Cruz, CA, USA). Electrophoresis reagents, such as gels, Tris-glycine SDS running buffer, and poly(vinylidene difluoride) (PVDF) membrane were from Novex Corp. (San Diego, CA, USA).

\section{Cell culture}

HepG2, a hepatoblastonema cell line used in this study, was obtained from Korean Cell Line Bank (Seoul, Korea) and grown in DMEM containing 100 units $/ \mathrm{ml}$ penicillin, $100 \mu \mathrm{g} / \mathrm{ml}$ streptomycin and $10 \% \mathrm{FBS}$, and maintained in a humidified atmosphere of $5 \% \mathrm{CO}_{2}$ in air at $37^{\circ} \mathrm{C}$. Two days after plating in $35 \mathrm{~mm}$ tissue culture dishes, HepG2 cells were serum starved for $24 \mathrm{~h}$ and then treated with different reagents. Cells were quickly frozen in liquid nitrogen and stored at $-70{ }^{\circ} \mathrm{C}$ until analysis.

\section{SDS-PAGE and immunoblotting}

Unless otherwise indicated, cells were lysed in ice-cold lysis buffer $(50 \mathrm{mM}$ Tris-HCl, $1 \%$ nonidet $\mathrm{P}-40$, $0.25 \%$ sodium deoxycholate, $150 \mathrm{mM} \mathrm{NaCl}, 1 \mathrm{mM}$ sodium orthovanadate, $1 \mathrm{mM} \mathrm{NaF}, 1 \mathrm{mM}$ phenylmethylsulfonyl fluoride, $1 \mu \mathrm{M}$ aprotinin, $1 \mu \mathrm{M}$ leupeptin and $1 \mu \mathrm{M}$ pepstatin A). The same amount of proteins was separated by SDS-PAGE on $4-20 \%$ polyacrylamide gels and electrotransferred onto PVDF membrane. The membrane was incubated in blocking buffer (5\% non-fat dry milk in Tris-buffered saline$0.1 \%$ Tween-20) for $1 \mathrm{~h}$ at room temperature and then probed with different primary antibodies (1:1000-1:5000). After a series of washes, the membrane was further incubated with different horseradish peroxidase-conjugated secondary antibodies (1:20001:10000). The signal was detected with an enhanced chemiluminescence detection system (Intron, Seongnam, Korea).

\section{Determination of caspase-3 activity}

After treatment with reagents, cells were collected, lysed in ice-cold $0.5 \mathrm{ml}$ caspase assay buffer (50 mmol/l Tris-HCl, pH 7.4, $150 \mathrm{mM} \mathrm{NaCl}, 1 \%$ nonidet $\mathrm{P}-40,0.25 \%$ sodium deoxycholate and $1 \mathrm{mmol} / \mathrm{l}$ EGTA) for $15 \mathrm{~min}$. After centrifugation at $12000 \boldsymbol{g}$ for $15 \mathrm{~min}$ at $4^{\circ} \mathrm{C}$, aliquots of supernatant were incubated with $10 \mu \mathrm{mol} / \mathrm{l}$ Ac-DEVD-AMC for $3 \mathrm{~h}$ at $37^{\circ} \mathrm{C}$. The fluorescence from the cleaved product was detected with a Spectrafluor multiwell fluorescence reader (Tecan, Grödig, Austria) at $360 \mathrm{~nm}$ and $465 \mathrm{~nm}$ wavelengths for excitation and emission respectively.

\section{Detection of apoptotic cells with flow cytometric analysis and $\mathrm{H} 33342$ staining}

The degree of apoptosis was determined by measuring the number of cells showing below the G1 DNA content from flow cytometric analysis after staining of cells with propidium iodide as originally described by Crissman \& Steinkamp (16). The samples were analyzed with a Coulter EpicsTM cytometer (Beckman, Fullerton, CA, USA). Ten thousand events were collected for each sample. An excitation wavelength of $488 \mathrm{~nm}$ and a fluorescence emission of $580 \mathrm{~nm}$ were used. Otherwise, cells were stained with a DNA-specific fluorescent dye (H33342) then observed under a fluorescent microscope equipped with a CoolSNAP-Pro color digital camera (Media Cybernetics, Meyer, Housten, TX, USA) to examine the degree of nuclear condensation.

\section{Measurement of ROS}

$\mathrm{H}_{2}$ DCFDA, a cell-permeable fluorogenic probe that is useful for the detection of ROS, was used to measure the degree of ROS accumulation within cells. Cultured 
cells were briefly washed once with D-PBS and further incubated in D-PBS containing $10 \mathrm{mmol} / \mathrm{l} \mathrm{H}_{2}$ DCFDA for $10 \mathrm{~min}$ at $37^{\circ} \mathrm{C}$. The fluorescence intensity was measured with a Spectrafluor multiwell fluorescence reader at $485 \mathrm{~nm}$ and $535 \mathrm{~nm}$ wavelengths for excitation and emission respectively, under constant conditions to allow quantitative comparisons of relative fluorescence intensity from cells with different treatments. Fluorescent cell images were instantly captured under a fluorescent inverted microscope equipped with a CoolSNAP-Pro color digital camera.

\section{Statistical analysis}

Statistical analysis was performed using an analysis program, StatView (Abacus Concepts, Berkeley, CA, USA). The Student's $t$-test was used to analyze the difference between control and experimental groups. $P<0.05$ was considered to be significant.

\section{Results}

\section{Insulin delays apoptosis induced by serum starvation or oxidative stress}

Our previous studies $(4,5)$ have shown that insulin delayed apoptosis induced by serum starvation in CHO-IR cells. However, it is not clear whether insulin can really play a role in inhibiting apoptosis in certain cells having intrinsic insulin receptors such as adipocytes, muscle cells or liver cells. HepG2 is a hepatoblastonema cell line that expresses intrinsic insulin receptors. HepG2 cells were preincubated in serum-free medium for $24 \mathrm{~h}$ and then washed with D-PBS twice, then treated with $100 \mathrm{nmol} / \mathrm{l}$ insulin for an additional $48 \mathrm{~h}$. The degree of apoptosis was determined with flow cytometric analysis measuring DNA content of each cell and counting the number of events below diploid $(<2 \mathrm{~N})$ DNA content (Fig. 1A). The percentages of apoptotic cells were $23.2 \pm 3.5 \%$ (control, serum-free) and $4.1 \pm 0.7 \%$ (100 nmol/l insulin) respectively. The

\section{A}
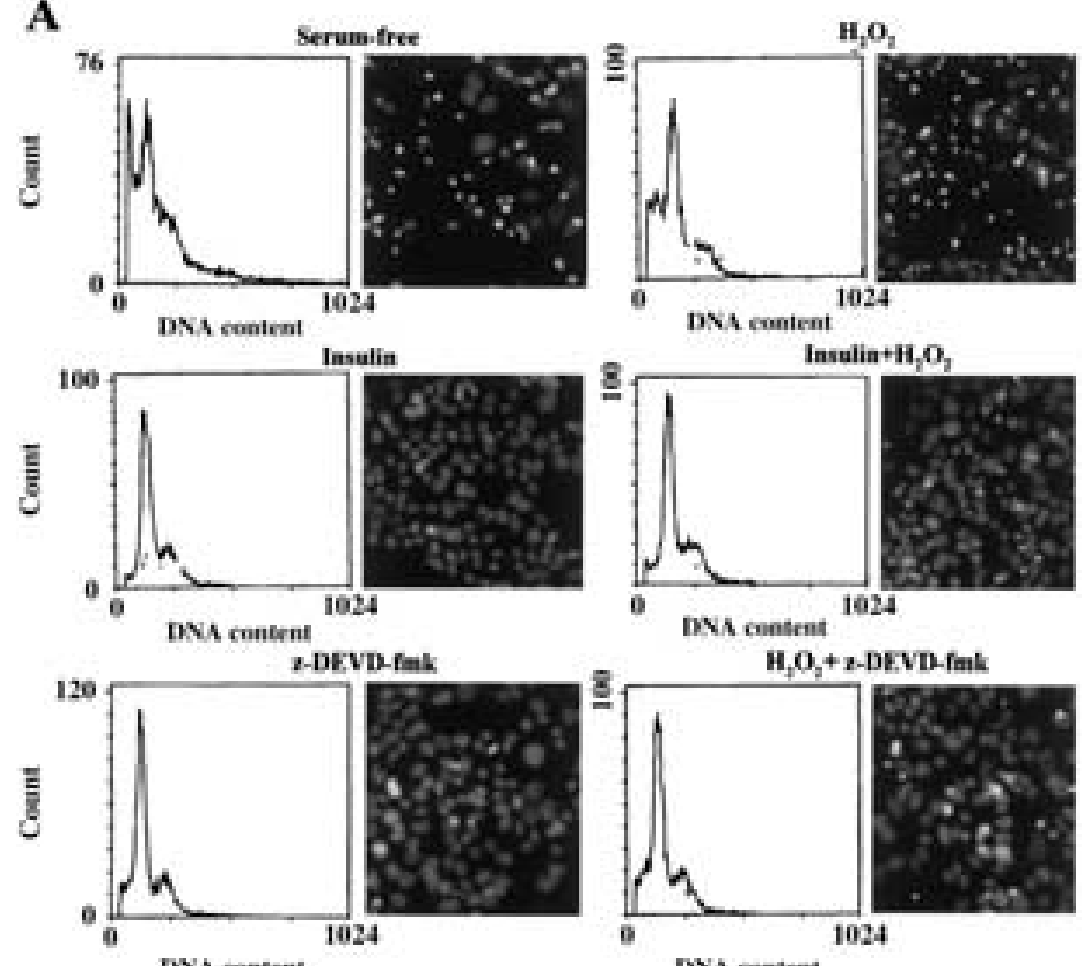

B
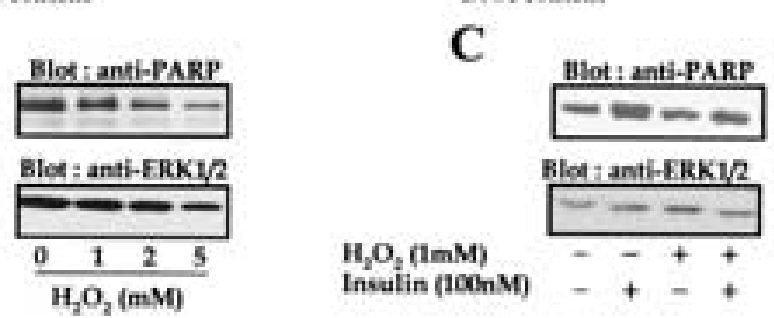

Figure 1 Insulin blocks apoptosis induced by serum starvation or $\mathrm{H}_{2} \mathrm{O}_{2}$ addition. (A) Cells were serum starved $(24 \mathrm{~h})$, preincubated with $10 \mu \mathrm{mol} / / \mathrm{z}$-DEVD-fmk ( $30 \mathrm{~min})$, and further incubated with $100 \mathrm{nmol} / \mathrm{l}$ insulin and $1 \mathrm{mmol} / \mathrm{l}$ $\mathrm{H}_{2} \mathrm{O}_{2}$ for an additional $48 \mathrm{~h}$. The degree of apoptosis is represented as the DNA content measured by flow cytometric analysis and the photographs show cells with highly condensed nuclei stained with $\mathrm{H} 33342$. (B) Proteolytic cleavage of PARP induced by $\mathrm{H}_{2} \mathrm{O}_{2}$ and $(\mathrm{C})$ its suppression by insulin after treatment of cells for $48 \mathrm{~h}$. Equal amounts of cell lysates were subjected to electrophoresis and analyzed by Western blot for PARP, and ERK as an internal standard. 
effect of $\mathrm{H}_{2} \mathrm{O}_{2}(1 \mathrm{mmol} / \mathrm{l})$ was also examined in order to determine whether an additional oxidative stress accelerates an apoptotic process induced by serum starvation. The addition of $\mathrm{H}_{2} \mathrm{O}_{2}$ significantly increased the percentage of apoptotic cells $(35.3 \pm 4.2 \%)$ compared with control groups $(P<0.05)$. Insulin treat-

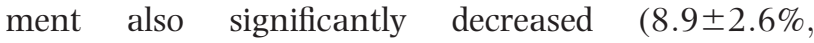
$P<0.01)$ the degree of apoptosis compared with $\mathrm{H}_{2} \mathrm{O}_{2}$ alone. To further confirm this finding, cells were stained with a DNA-specific fluorescent dye, H33342, to observe the degree of nuclear condensation, which is an apoptotic phenomenon (Fig. 1A).
A number of cells incubated in serum-free medium or treated with $\mathrm{H}_{2} \mathrm{O}_{2}$ for $48 \mathrm{~h}$ showed highly condensed nuclei. Insulin treatment clearly decreased the number of cell with condensed nuclei in both groups. We also investigated whether the activation of caspase- 3 is associated with the apoptotic process induced by serum starvation or oxidative stress. z-DEVD-fmk, a cell-permeable caspase- 3 inhibitor, effectively protected cells from apoptosis by serum starvation or $\mathrm{H}_{2} \mathrm{O}_{2}$ treatment from the results of flow cytometric analysis and H33342 staining. The degree of proteolytic cleavage of PARP, a target molecule of caspases, was parallel

\section{A}

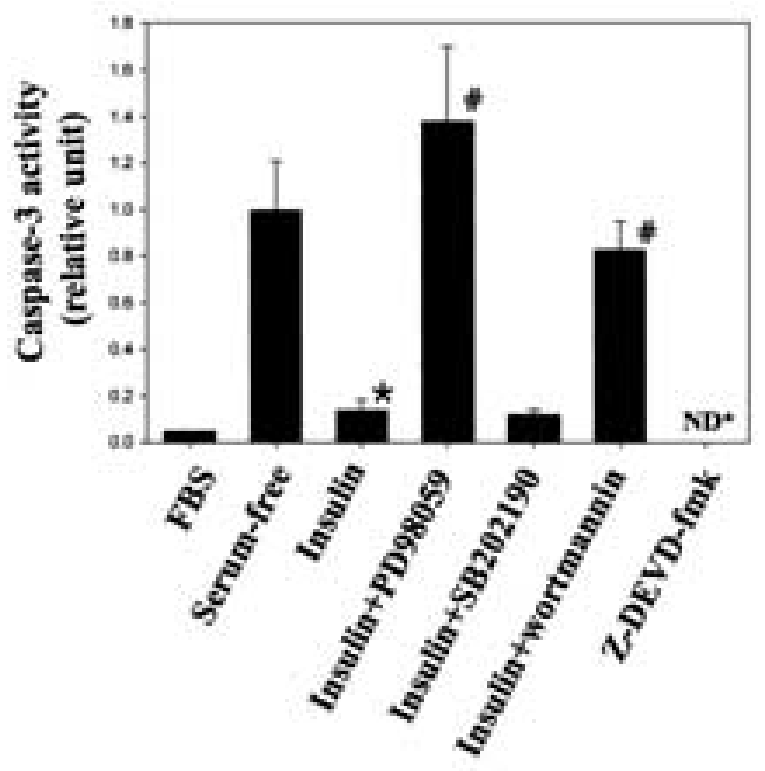

B

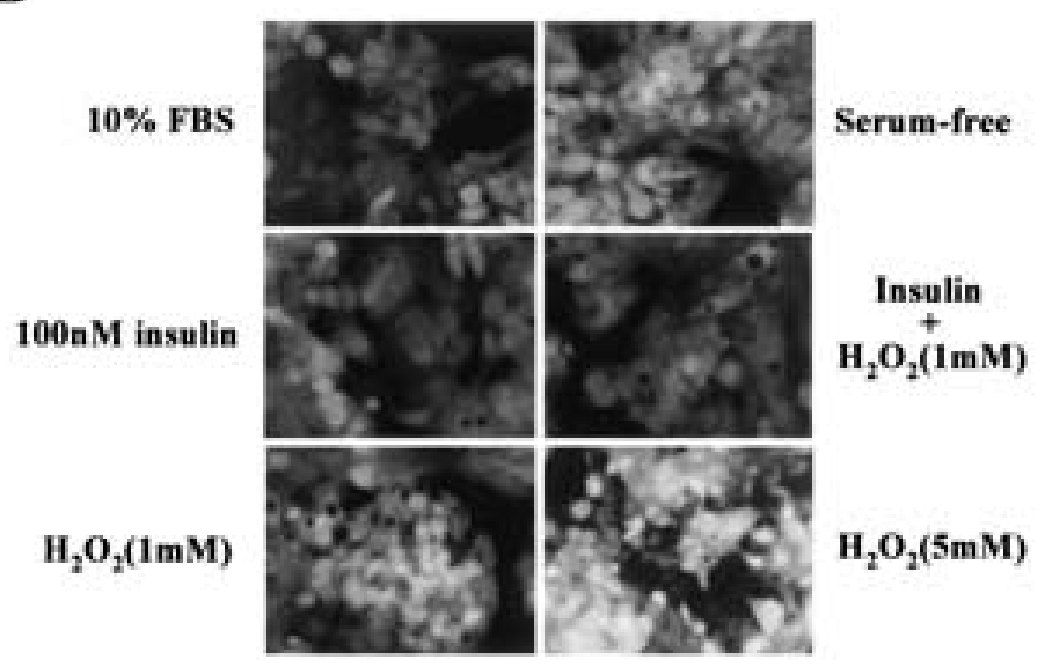

Figure 2 Insulin suppresses caspase-3 stimulation and ROS production induced by serum starvation. (A) HepG2 cells were serum starved for $24 \mathrm{~h}$ and preincubated with inhibitors for $30 \mathrm{~min}$ before insulin addition as described in Results. Caspase-3 activity was measured at $24 \mathrm{~h}$ after insulin treatment and is represented as relative units. Results are the means \pm S.E.M. of three separate experiments. ${ }^{*} P<0.05$ vs serum free; ${ }^{\#} P<0.05$ vs insulin; *ND, non-detected. (B) Dichlorofluorescein (DCF) fluorescence from cells imaged with a CoolSNAP-Pro digital camera attached to the inverted fluorescent microscope. Cells were serum starved for $24 \mathrm{~h}$ and further treated with insulin and/or $\mathrm{H}_{2} \mathrm{O}_{2}$ for an additional $3 \mathrm{~h}$. 
with the dose of $\mathrm{H}_{2} \mathrm{O}_{2}$ (Fig. 1B). The integrity of PARP was increased by insulin treatment compared with serum starvation. $\mathrm{H}_{2} \mathrm{O}_{2}$-induced PARP cleavage was also effectively blocked by insulin (Fig. 1C). These results suggested that insulin can protect HepG2 cells from apoptosis induced by serum starvation or oxidative stress.

\section{Insulin suppresses caspase-3 activity and ROS production}

The caspase family of cysteine proteases plays a pivotal role in mediating apoptosis through the proteolysis of specific targets that include PARP, the nuclear lamins and caspase-dependent DNase $(17,18)$. The function
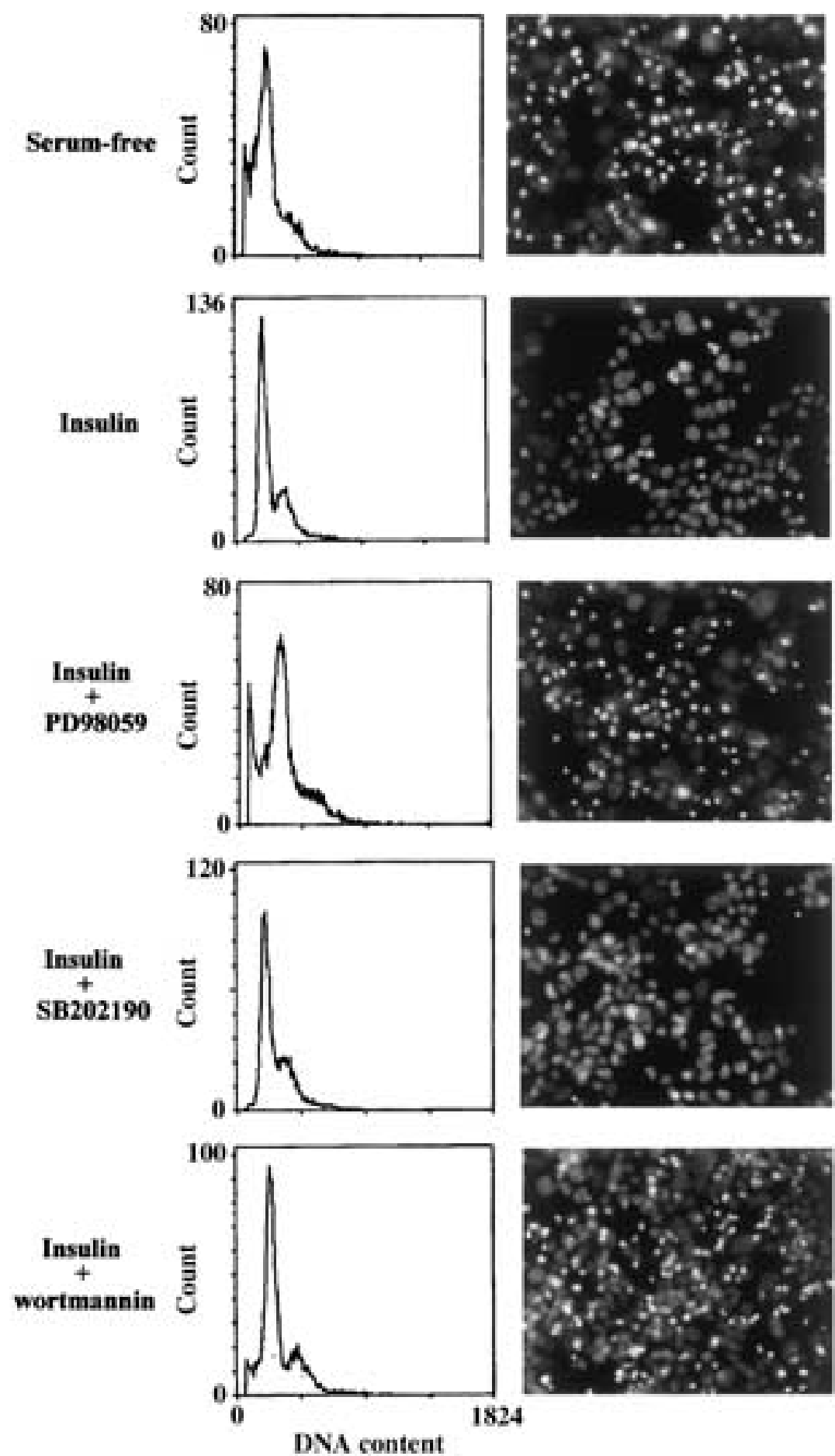

Figure 3 The anti-apoptotic activity of insulin is sensitive to ERK inhibition and PI3 kinase inhibition. Cells were serum starved $(24 \mathrm{~h})$, preincubated with inhibitors for $30 \mathrm{~min}$ and further incubated with insulin for an additional $48 \mathrm{~h}$. The degree of apoptosis is represented as the DNA content measured by flow cytometric analysis and the photographs show cells with highly condensed nuclei stained with $\mathrm{H} 33342$. 
of caspase-3 activity has been described (19) as being involved in the execution of apoptosis in a tissue-, cell type- or death stimulus-specific manner. From the results shown in Fig. $1 \mathrm{~A}$, serum starvation or $\mathrm{H}_{2} \mathrm{O}_{2}$ treatment may induce apoptosis via mechanisms including caspase- 3 activation. We further investigated the effect of insulin on the caspase- 3 activity and intracellular ROS accumulation. Moreover, inhibitors against signaling molecules activated in response to insulin were administered to cultured cells to examine which signaling steps play significant roles in protecting cells from apoptosis. First, caspase- 3 activity was measured $24 \mathrm{~h}$ after insulin $(100 \mathrm{nmol} / \mathrm{l})$ treatment in the absence or presence of inhibitors as indicated (Fig. 2A). Serum starvation sharply elevated caspase-3 activity when compared with the presence of $10 \%$ FBS in the medium. Insulin markedly suppressed caspase-3 activity induced by serum starvation. Caspase3 activity was undetectable where z-DEVD-fmk $(10 \mu \mathrm{mol} / \mathrm{l})$ was added, demonstrating the specific nature of this assay. Inhibition of ERK with PD98059 $(50 \mu \mathrm{mol} / \mathrm{l})$ and inhibition of PI3 kinase with wortman- nin (100 nmol/l) markedly blocked insulin’s function in suppressing caspase-3 activity, whereas inhibition of p38Map kinase with SB202190 (10 $\mu \mathrm{mol} / \mathrm{l})$ showed no effect. We also examined whether insulin affects intracellular ROS accumulation (Fig. 2B). $\mathrm{H}_{2} \mathrm{O}_{2}$ $(1 \mathrm{mmol} / \mathrm{l})$ was also added together with insulin to determine whether insulin can diminish the amount of intracellular ROS increased by $\mathrm{H}_{2} \mathrm{O}_{2}$ addition. From the microscopic observations, the intensity of fluorescence from dichlorofluorescein (DCF) oxidized by intracellular ROS was increased where cells were incubated for $3 \mathrm{~h}$ in serum-free medium or in medium containing $\mathrm{H}_{2} \mathrm{O}_{2}(1-5 \mathrm{mmol} / \mathrm{l})$. Insulin lowered both of the intensities of fluorescence elicited by serum starvation and $\mathrm{H}_{2} \mathrm{O}_{2}$ addition.

\section{Inhibition of PI3 kinase and ERK block the anti-apoptotic activity of insulin}

Activation of the insulin receptor increases PI3 kinase activity, whose function has been associated with the anti-apoptotic signaling in various cell types $(20,21)$.

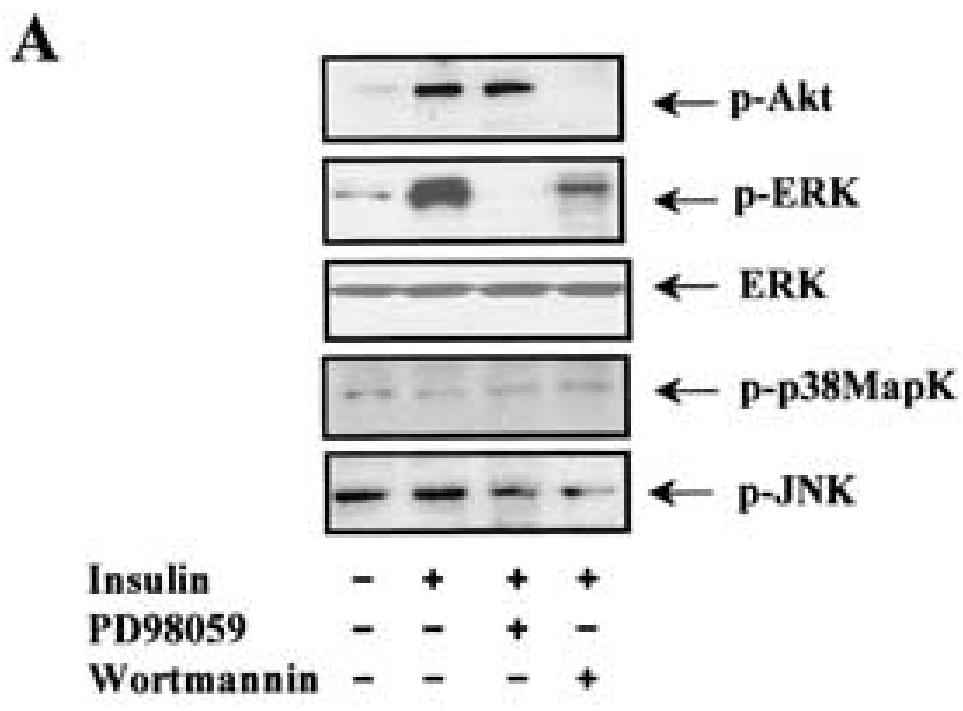

B

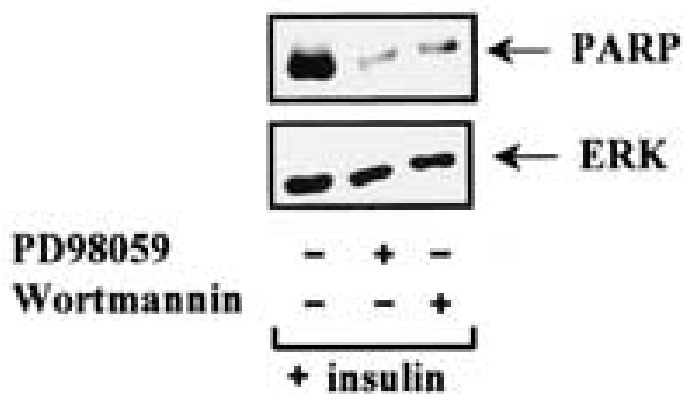

Figure 4 ERK activation is necessary for the antiapoptotic protection of cells by insulin. Cells were serum starved for $24 \mathrm{~h}$, preincubated with inhibitors for $30 \mathrm{~min}$ and further incubated with insulin for (A) 5 min or (B) $36 \mathrm{~h}$. Equal amounts of cell lysates were subjected to electrophoresis and analyzed by Western blot for phospho(p)-Akt, p-ERK, p-p38Map kinase (p38MapK), p-JNK, PARP, and ERK as an internal standard. 
However, in CHO-IR cells, the activation of PI3 kinase by insulin did not play a role in protecting cells from apoptosis induced by serum starvation because insulin's anti-apoptotic protection was not altered by wortmannin or LY294002 (4), two chemically unrelated inhibitors of PI3 kinase. In the present study, however, HepG2 cells pretreated with $100 \mathrm{nmol} / \mathrm{l}$ wortmannin were apoptotic to a large extent even in the presence of insulin (Fig. 3). A specific inhibitor of MAP kinase kinase 1 (MEK1), PD98059, was also used to assess the role of ERK activity in insulin-mediated protection against apoptosis. The protective effect of insulin was markedly blocked by $50 \mu \mathrm{mol} / \mathrm{l}$ PD98059 (Fig. 3) and the insulin stimulation of ERK activity was also completely blocked (Fig. 4A). Unexpectedly, insulin stimulation of ERK activity was clearly suppressed by wortmannin whereas Akt stimulation by insulin was unaffected by PD98059 (Fig. 4A). Neither active JNK nor p38Map kinase, other members of Map kinase families, were changed in the presence of insulin (Fig. 4A). Separate experiments were performed to determine the effects of those inhibitors on the cleavage of PARP (Fig. 4B). Treatment of cells with PD98059 or wortmannin accelerated PARP cleavage, which was suppressed by insulin. These results suggest that the anti-apoptotic function of insulin is mediated by PI3 kinase as well as ERK, but not by Akt.

\section{Discussion}

In the present study, we examined the ability of insulin to exert an anti-apoptotic function in HepG2 cells and its related signaling pathways. Insulin is a potent survival factor in different cell systems $(1-3)$. Our present study has shown that insulin inhibits apoptosis induced by serum starvation in HepG2 cells that express insulin receptors. This finding is in agreement with our previous results using $\mathrm{CHO}$-IR cells $(4,5)$ but has different kinetics. HepG 2 cells were apoptotic at least $36 \mathrm{~h}$ later in serum-free conditions whereas most CHO-IR cells were readily apoptotic within $24 \mathrm{~h}$ (5) from the flow cytometric analysis. The degree of intracellular ROS accumulation and caspase-3 activity was paralleled by the progress of apoptosis. Information regarding the biological significance of ROS has increased considerably in recent years, revealing diverse functions $(22,23)$. Exposure of cells to ROS in a variety of experimental systems leads to apoptosis and to cell damage (23). Moreover, targeted disruption of inducible nitric oxide synthase (iNOS) protects against insulin resistance in muscle, indicating the involvement of iNOS in the development of muscle insulin resistance (24). Other studies have also reported that oxidative stress reduces glucose uptake in response to insulin through the changes of the level of glucose transporter (GLUT) 1 and GLUT4 transcription $(25,26)$. However, at low concentrations, ROS may function as physiological mediators of cellular responses (27). For example, several studies have shown that $\mathrm{H}_{2} \mathrm{O}_{2}$ had insulinomimetic effects in different cell systems $(12,28,29)$. A very recent study has suggested that the generation of $\mathrm{H}_{2} \mathrm{O}_{2}$ in response to insulin is integral to the activation of the distal insulin signaling cascade, stimulating PI3 kinase, Akt and then glucose uptake in adipocytes (13). Growth factors such as platelet-derived growth factor and basic fibroblast growth factor are also capable of producing ROS $(30,31)$. From these results it appears that the transient generation of ROS and the prolonged accumulation of ROS might have distinctive significance with regard to their signaling pathways and physiological roles. In the present study, serum starvation induced ROS accumulation, which was suppressed by the addition of insulin. Caspase- 3 activity was also increased by serum starvation, indicating an aspect of the proapoptotic activities of ROS. The involvement of caspase-3 stimulation in ROS-induced apoptotic process is supported by the protection of cells from apoptosis by the addition of z-DEVD-fmk, an inhibitor of caspase-3. Moreover, n-acetylcysteine, a scavenger of $\mathrm{H}_{2} \mathrm{O}_{2}$, blocked caspase- 3 activation and protected cells from apoptosis induced by serum starvation in HepG2 cells in a separate experiment (data not shown). However, in CHO-IR cells, z-DEVD-fmk failed to rescue cells from apoptosis whereas it inhibited caspase-3 activity (5). These results suggest that the apoptotic steps caused by serum starvation are different between CHO-IR and HepG2 cells with respect to the significance of caspase-3. The present study has shown a strong relevance of insulin's antiapoptotic activity to the suppression of ROS accumulation and the subsequent inhibition of caspase- 3 activation induced by serum starvation in HepG2 cells. However, we did not examine the fluctuation in ROS at the early phases after insulin treatment; thus, the significance of the transient changes in intracellular ROS content remains to be clarified.

The signal transduction pathways stimulated by insulin to confer anti-apoptotic protection were also investigated. Various inhibitors of key steps in signaling cascades activated by growth factors have been widely used and have provided important insights into the understanding of the role of signaling molecules (3234). In the present study, insulin led to the activation of Akt, which was fully inhibited by $100 \mathrm{nmol} / \mathrm{l}$ wortmannin. The anti-apoptotic protection of insulin was also sharply blocked by the addition of wortmannin, suggesting the role of PI3 kinase in protecting cells from apoptosis. Insulin stimulated the ERK activity, which was completely blocked by PD98059, an inhibitor of ERK activation. Interestingly, the stimulation of ERK by insulin was clearly suppressed by wortmannin. Blockade of ERK activation by PI3 kinase inhibitors has been reported in a few cell systems. For example, wortmannin blocks the activation of ERK by kainite in rat striatal slices (35) and by acetylcholine in colonic 
smooth muscle (36). However, the mechanism by which the activation of PI3 kinase plays a role in stimulating ERK activity is not yet understood. Vanadium salts, which have insulinomimetic effects, activate Ras, Raf- 1 and MEK and their activation can be blocked by wortmannin (37). Moreover, a member (PI3K $\gamma$ ) of the PI3 kinase family activates ERK as well as Akt (38). Tyrosine phosphorylation of Gab1, a Grb-2associated binder, also plays a pivotal role in PI3 kinase-dependent ERK activation in response to endothelin-1 which activates G-protein-coupled receptor signaling cascades (39). On the contrary, Akt inhibits the Raf-MEK-ERK pathway in the course of myotube differentiation (40). Thus, the PI3 kinaseAkt axis might affect the Raf-MEK-ERK pathway positively or negatively in different cell systems or under different physiological conditions. Our data showed that the activations of PI3 kinase and ERK in response to insulin play roles in protecting cells from apoptosis. However, the significance of Akt in exerting the antiapoptotic activity of insulin is not yet clear, because the activity of Akt was still considerably high, even in cells which were clearly made apoptotic by the addition of PD98059 together with insulin. Blockade of insulininduced ERK activation by PD98059 or wortmannin was paralleled by the stimulation of caspase- 3 activity and the induction of apoptosis. We also tested whether insulin can affect the activities of JNK and p38Map kinase, other members of the MAP kinase families. Neither the activities of JNK nor p38Map kinase were changed by the addition of insulin. From these results, it is suggested the only ERK among the members of the MAP kinase families plays a role in protecting HepG2 cells from apoptosis in response to insulin.

Taken together, we have demonstrated that the antiapoptotic action of insulin is paralleled by the reduction of ROS generation and suppression of caspase- 3 stimulation induced by serum starvation or $\mathrm{H}_{2} \mathrm{O}_{2}$ addition in HepG2 cells. Moreover, insulin's survival function is dependent on the activation of PI3 kinase and ERK.

\section{Acknowledgements}

This work is supported by Korea Research Foundation Grant (KRF-2000-015-DP0426).

\section{References}

1 Diaz B, Pimentel B, De Pablo F \& De La Rosa EJ. Apoptotic cell death of proliferating neuroepithelial cells in the embryonic retina is prevented by insulin. European Journal of Neuroscience 199911 1624-1632.

2 Bertrand F, Atfi A, Cadoret A, L'Allemain G, Robin H, Lascols O et al. A role for nuclear factor kappaB in the antiapoptotic function of insulin. Journal of Biological Chemistry 1998273 2931-2938.

3 Rampalli AM \& Zelenka PS. Insulin regulates expression of c-fos and c-jun and suppresses apoptosis of lens epithelial cells. Cell Growth and Differentiation 19956 945-953.
4 Lee-Kwon W, Park D, Baskar PV, Kole S \& Bernier M. Antiapoptotic signaling by the insulin receptor in Chinese hamster ovary cells. Biochemistry 199837 15747-15757.

5 Park D, Pandey SK, Maksimova E, Kole S \& Bernier M. Aktdependent antiapoptotic action of insulin is sensitive to farnesyltransferase inhibitor. Biochemistry 200039 12513-12521.

6 Cross CE, Halliwell B, Borish ET, Pryor WA, Ames BN, Saul RL et al. Oxygen radicals and human disease. Annals of Internal Medicine $1987107526-545$.

7 Wolff SP, Jiang ZY \& Hunt JV. Protein glycation and oxidative stress in diabetes mellitus and aging. Free Radical Biology and Medicine 199110 339-352.

8 Nourooz-Zadeh J, Tajaddini-Sarmadi J, McCarthy S, Betteridge DJ \& Wolff SP. Elevated levels of authentic plasma hydroperoxides in NIDDM. Diabetes 199544 1054-1058.

9 Hansen LL, Ikeda Y, Olsen GS, Busch AK \& Mosthaf L. Insulin signaling is inhibited by micromolar concentrations of $\mathrm{H}(2) \mathrm{O}(2)$. Evidence for a role of $\mathrm{H}(2) \mathrm{O}(2)$ in tumor necrosis factor alphamediated insulin resistance. Journal of Biological Chemistry 1999 $27425078-25084$.

10 Tirosh A, Poatshnik R, Boshan N \& Rudich A. Oxidative stress disrupts insulin-induced cellular redistribution of insulin receptor substrate-1 and phosphatidylinositol 3-kinase in 3T3-L1 adipocytes. A putative cellular mechanism for impaired protein kinase B activation and GLUT4 translocation. Journal of Biological Chemistry 1999274 10595-10602.

11 Mukherjee SP, Lane RH \& Lynn WS. Endogenous hydrogen peroxide and peroxidative metabolism in adipocytes in response to insulin and sulfhydryl reagents. Biochemical Pharmacology 1978 27 2589-2594.

12 May JM \& de Haen C. The insulin-like effect of hydrogen peroxide on pathways of lipid synthesis in rat adipocytes. Journal of Biological Chemistry 1979254 9017-9021.

13 Mahadev K, Wu X, Zilbering A, Zhu L, Lawrence JTR \& Goldstein BJ. Hydrogen peroxide generated during cellular insulin stimulation is integral to activation of the distal insulin signaling cascade in 3T3-L1 adipocytes. Journal of Biological Chemistry 2001 $27648662-48669$.

14 Mahadev K, Zilbering A, Zhu L \& Goldstein BJ. Insulin-stimulated hydrogen peroxide reversibly inhibits protein-tyrosine phosphatase $1 \mathrm{~b}$ in vivo and enhances the early insulin action cascade. Journal of Biological Chemistry 2001276 21938-21942.

15 Virkamaki A, Ueki K \& Kahn CR. Protein-protein interaction in insulin signaling and the molecular mechanisms of insulin resistance. Journal of Clinical Investigation 1999103 931-943.

16 Crissman HA \& Steinkamp JA. Rapid, simultaneous measurement of DNA, protein, and cell volume in single cells from large mammalian cell populations. Journal of Biological Chemistry $1973 \mathbf{5 9}$ 766-771.

17 Stennicke HR \& Salvasen GS. Properties of the caspases. Biochimica et Biophysica Acta 19981387 17-31.

18 Nagata S. Apoptotic DNA fragmentation. Experimental Cell Research 2000256 12-18.

19 Porter AG \& Janicke RU. Emerging roles of caspase-3 in apoptosis. Cell Death and Differentiation 19996 99-104.

20 Yao R \& Cooper GM. Effects of $\mathrm{H}_{2} \mathrm{O}_{2}$ on protein tyrosine phosphatase activity in HER14 cells. Science 1995267 2003-2006.

21 Minshall C, Arkins S, Freund GG \& Kelley KW. Requirement for phosphatidylinositol $3^{\prime}$-kinase to protect hemopoietic progenitors against apoptosis depends upon the extracellular survival factor. Journal of Immunology $1996156939-947$.

22 Palmer HJ \& Paulson KE. Reactive oxygen species and antioxidants in signal transduction and gene expression. Nutrition Reviews 199755 353-361.

23 Papa S \& Skulachev VP. Reactive oxygen species, mitochondria, apoptosis and aging. Molecular and Cellular Biochemistry 1997 174 305-319.

24 Perreault M \& Marette A. Targeted disruption of inducible nitric oxide synthase protects against obesity-linked insulin resistance in muscle. Nature Medicine 20017 1138-1143. 
25 Rudich A, Kozlovsky N, Potashnik R \& Bashan N. Oxidant stress reduces insulin responsiveness in 3T3-L1 adipocytes. American Journal of Physiology 1997272 E935-E940.

26 Rudich A, Tirosh A, Potashnik R, Hemi R, Kanety H \& Bashan N. Prolonged oxidative stress impairs insulin-induced GLUT4 translocation in 3T3-L1 adipocytes. Diabetes $1998 \mathbf{4 7} 1562-1569$.

27 Schreck R, Rieber P \& Baeuerle PA. Reactive oxygen intermediates as apparently widely used messengers in the activation of the NFkappa B transcription factor and HIV-1. EMBO Journal 199110 $2247-2258$.

28 Heffetz D, Bushkin I, Dror R \& Zick Y. The insulinomimetic agents $\mathrm{H}_{2} \mathrm{O}_{2}$ and vanadate stimulate protein tyrosine phosphorylation in intact cells. Journal of Biological Chemistry $19902652896-2902$.

29 Wilden PA \& Broadway D. Combination of insulinomimetic agents $\mathrm{H}_{2} \mathrm{O}_{2}$ and vanadate enhances insulin receptor mediated tyrosine phosphorylation of IRS-1 leading to IRS-1 association with the phosphatidylinositol 3-kinase. Journal of Cellular Biochemistry $1995 \mathbf{5 8} 279-291$.

30 Lo YYC \& Cruz TF. Involvement of reactive oxygen species in cytokine and growth factor induction of c-fos expression in chondrocytes. Journal of Biological Chemistry $199527011727-11730$.

31 Sundaresan M, Yu Z-X, Ferrans V, Irani K \& Finkel T. Requirement for generation of $\mathrm{H}_{2} \mathrm{O}_{2}$ for platelet-derived growth factor signal transduction. Science 1995270 296-299.

32 Farrelly N, Lee YJ, Oliver J, Dive C \& Streuli H. Extracellular matrix regulates apoptosis in mammary epithelium through a control on insulin signaling. Journal of Cell Biology 1999 144 1337-1347.

33 Kulik G \& Webber MJ. Akt-dependent and -independent survival signaling pathways utilized by insulin-like growth factor I. Molecular and Cellular Biology $1998186711-6718$.

34 Erin PE, Schremser EJ \& Cooper GM. B-Raf inhibits cell death downstream of cytochrome $\mathrm{c}$ release from mitochondria by activating the MEK/Erk pathway. Molecular and Cellular Biology $1999195308-5315$.

35 Fuller G, Veitch K, Ho LK, Cruise L \& Morris BJ. Activation of p44/p42 MAP kinase in striatal neurons via kainate receptors and PI3 kinase. Molecular Brain Research 200189 126-132.

36 Yamboliev IA, Wiesmann KM, Singer CA, Hedges JC \& Gerthoffer WT. Phosphatidylinositol 3-kinases regulate ERK and p38 MAP kinases in canine colonic smooth muscle. American Journal of Physiology Cell Physiology 2000279 C352-C360.

37 Pandey SK, Theberge JF, Bernier M \& Sriastava AK. Phosphatidylinositol 3-kinase requirement in activation of the ras/C-raf1/MEK/ERK and p70(s6k) signaling cascade by the insulinomimetic agent vanadyl sulfate. Biochemistry 199938 14667-14675.

38 Bondeva T, Pirola L, Bulgarelli-Leva G, Rubio I, Wetzker R \& Wymann MP. Bifurcation of lipid and protein kinase signals of PI3K $\gamma$ to the protein kinases PKB and MAPK. Science 1998 282 293-296.

39 Bisotto S \& Fixman ED. Src-family tyrosine kinases, phosphoinositide 3-kinase and Gab1 regulate extracellular signal-regulated kinase 1 activation induced by the type A endothelin-1 G-protein-coupled receptor. Biochemical Journal 2000360 77-85.

40 Rommel C, Clarke BA, Zimmermann S, Nunez L, Rossman R, Reid $\mathrm{K}$ et al. Differentiation stage-specific inhibition of the Raf-MEKERK pathway by Akt. Science 1999286 1738-1741.

Received 8 May 2002

Accepted 23 September 2002 